\title{
Estudo dos efeitos de aumentos no custo do combustível na demanda por transporte aéreo doméstico
}

\author{
Helen Feuser Fernandes ${ }^{1}$, Cláudio Jorge Pinto Alves², Alessandro Vinícius Marques de Oliveira ${ }^{3}$
}

\begin{abstract}
Resumo: Um choque permanente de custos das empresas, quando repassados aos consumidores via transmissão de preços, pode afetar o comportamento de mercado das mesmas e gerar um potencial dano ao bem-estar econômico. O presente trabalho busca investigar esse fenômeno no setor de transporte aéreo, onde os custos com combustível representam uma parcela relevante dos custos operacionais. Efetuou-se uma quantificação dos impactos na demanda por viagens domésticas quando há repasses dos aumentos simulados nos custos do combustível para os preços das passagens. O estudo efetua uma modelagem econométrica de demanda e construção de cenários contrafatuais em uma análise de bem-estar econômico. Para a estimação de demanda, utilizou-se uma modelagem com estimador de variáveis instrumentais. Os resultados indicam que um aumento de cinquenta por cento no custo do combustível, combinado com um movimento de duopolização do mercado, provocaria perdas de quase quarenta por cento no bem-estar econômico do consumidor.
\end{abstract}

Palavras-chave: Combustível de aviação. Companhia aérea. Custo. Demanda.

\begin{abstract}
A permanent shock in the cost of companies, when passed through to consumers by price transmission, may affect their behavior in the market and create potential damage to economic welfare. This paper investigates this phenomenon in the airline industry, where fuel costs account for a significant portion of total operating costs. We assessed the impact on demand for domestic travel of simulated increases in airline fuel costs and the resulting pass-through to prices. Our study develops an econometric model of demand and creates counterfactual scenarios for an economic welfare analysis. We employed an instrumental variables estimator in our econometric demand modelling. Results indicated that an increase of fifty percent in fuel costs, along with a change of conduct of firms towards duopoly behavior, would cause losses of nearly forty percent in the economic welfare of consumers.
\end{abstract}

Keywords: Jet fuel. Airline. Cost. Demand.

\section{INTRODUÇÃO}

O objetivo do presente estudo é desenvolver um modelo econométrico com vistas a estimar a influência dos custos na demanda aeroportuária causadas por choques permanentes de custo no combustível de companhias aéreas. Para isso, tem-se como objeto de estudo a demanda doméstica do Aeroporto Internacional de Brasília. Desenvolveu-se um modelo econométrico com uso de estimador de variáveis instrumentais e implementou-se uma bateria de testes de diagnósticos, sensibilidade e análises de robustez com o intuito de promover a seleção do modelo. Com base nas estimativas obtidas, efetuou-se a criação de cenários contrafatuais e comparações com um cenário-base, onde au-

\footnotetext{
1 Instituto Tecnológico de Aeronáutica - Departamento de Transporte Aéreo (helen.fernandes@gmail.com).

2 Instituto Tecnológico de Aeronáutica - Departamento de Transporte Aéreo (claudioj@ita.br).

3 Instituto Tecnológico de Aeronáutica - Departamento de Transporte Aéreo (a.v.m.oliveira@gmail.com).
}

Manuscrito recebido em 26/06/2014 e aprovado para publicação em 06/09/2014. Este artigo é parte de TRANSPORTES v. 22, n. 3, 2014. ISSN: 2237-1346 (online).

DOI: http://dx.doi.org/10.14295/transportes.v22i3.810. mentos simulados de custos são aplicados para análise quantitativa de métricas de bem-estar econômico.

O Aeroporto Internacional de Brasília faz parte de um grupo de 20 aeroportos que, juntos, correspondem a $90 \%$ do movimento total de passageiros do Brasil, sendo um dos quatro mais expressivos em geração de tráfego, apresentando na última década um crescimento significativo. Em 2009, o movimento de passageiros por ano era de 12,2 milhões (McKinsey \& Company, 2010). O aeroporto de Brasília é um dos principais hubs do país, concentrando grande parcela de origem, destino e conexões para aeroportos domésticos. A demanda é motivada principalmente por lazer e negócios.

Estudos da demanda do transporte aéreo possuem sua relevância atrelada à necessidade de melhor planejar o setor, permitindo às autoridades e empresas uma antecipação de questões de tomada de decisão estratégica. O presente estudo visa simular impactos econômicos de alterações em uma variável de custos. Definiremos como impacto tudo aquilo que tira o mercado do 
equilíbrio previamente estabelecido. $\mathrm{Na}$ análise de "choque" de custo será adotado o elemento "combustível" como agente de perturbação. De acordo com Hsu e Eie (2013), no geral, o custo do combustível de aviação tem uma fatia de $30 \%$ nos custos operacionais, sendo o preço do petróleo e a forma pela qual esse valor será repassado ao usuário do transporte aéreo fatores de grande preocupação para as companhias aéreas.

As companhias aéreas trabalham com o objetivo de minimizar as consequências dessas flutuações do combustível de aviação (em especial, as flutuações em curto prazo) no preço das passagens aéreas, procurando manter a demanda. Sobretudo devido às pressões concorrenciais, sugerem Lim e Hong (2014) que nem sempre o ônus de um aumento inesperado do petróleo (e do combustível) deveria ser repassado para os clientes pelas companhias aéreas. Os autores se concentram no efeito do "fuel hedging" praticado por algumas companhias aéreas, ou seja, o contrato financeiro de risco que fixa o preço do insumo a ser pago no futuro e que potencialmente poderia manter os custos operacionais fixos. Entretanto, a literatura tem mostrado evidências justamente do contrário, ou seja, de um repasse pelo menos parcial das pressões em custos. Ryerson e Hansen (2013), por exemplo, concluem que, diante de pressões inflacionárias do insumo, ainda existe pouco espaço para gerenciamento de custos pelas empresas aéreas. Chao e Hsu (2014) analisam o transporte de carga aérea e concluem que, quando há aumento do combustível, há também aumento das taxas dos fretes.

O presente estudo efetua uma análise de bem-estar econômico do transporte aéreo dados possíveis choques de custos (simulados) com combustíveis das companhias aéreas. Basso e Zhang (2008) apresentam um estudo teórico de bem-estar para o setor, concluindo que há maior ineficiência de mercado quanto menor o grau de competição entre as companhias aéreas. Lu e Pagliari (2004) compararam os modelos de regulação Single-Till e Dual-Till em relação à precificação dos aeroportos e o bem-estar de ambos os cenários. No caso do presente estudo, diferentemente da literatura prévia, uma análise empírica de bem-estar econômico é realizada com estimação numérica das principais métricas de bem-estar - os excedentes do consumidor e produtor. Como contribuição, temos o desenvol- vimento de um modelo econométrico com uso de estimador de variáveis instrumentais para controle de endogenia da variável preço para produzir estimativas mais consistentes de bemestar econômico no mercado.

Este trabalho está dividido da seguinte forma: na Seção 2 são analisados os dados de entrada do modelo econométrico e os testes neles realizados; a Seção 3 abre a discussão da modelagem econométrica da demanda aeroportuária e os problemas econométricos controlados no modelo; as simulações de impactos de bem-estar econômico são realizadas na Seção 4; por último, na conclusão são feitas as últimas ponderações e discussões em torno de todos os resultados do estudo aqui realizado.

\section{APRESENTAÇÃO DOS DADOS}

Para a criação do modelo econométrico foram utilizadas bases de dados para compor as variáveis do problema. Para que um modelo tenha um bom ajuste, é de fundamental importância para o desenvolvimento do modelo econométrico, a escolha das variáveis e a interação entre elas, além da relevância de cada uma em explicar o regressando.

O regressando, ou o " $y$ " (variável dependente) da equação é a demanda, aqui chamada de "Inpaxdl". Sendo que o paxdl é composto pelo movimento de passageiros domésticos locais do lugar adotado para estudo (Aeroporto Internacional de Brasília). Esta variável representa o total de passageiros embarcados somados aos passageiros desembarcados, em voos domésticos e diretos, sem conexões - ou seja, os passageiros "locais". Foi utilizado logaritmo nessa variável, pois se entende que a taxa de crescimento da demanda de passageiros seja maior do que a variação das variáveis explicativas, logo, o modelo log-lin representa melhor o comportamento da demanda. Através dessa variável é possível estimar a demanda em contrafatuais, ou seja, possíveis cenários que poderiam ter acontecido em um determinado período de tempo, em uma simulação de cenários. Analisando dessa forma o impacto que cada parcela (variáveis independentes), que integra o modelo, influencia a demanda e o efeito que estas têm sobre ela. Foram tomados valores mensais de passageiros, no período de janeiro de 2002 até dezembro de 2012, através dos relatórios da In- 
fraero, da Superintendência de Desenvolvimento Aeroportuário - DPDR e dados de movimento operacional.

Uma das variáveis de geração de dados da demanda é o yield, sendo essa uma variável proxy do modelo. As variáveis proxies são utilizadas para medir algo que muitas vezes não é mensurável, mas que tem uma forte relação com o que se deseja apresentar. O yield é um indicador que representa a tarifa média paga pelo passageiro por quilômetro voado. Tal indicador é muito útil para comparar os preços entre linhas aéreas com diferentes distâncias e está diretamente relacionada com o aumento ou diminuição da demanda, pois os passageiros são afetados pelo valor das tarifas aéreas. Dessa forma, de acordo com a Teoria Econômica, é esperado o sinal negativo para essa variável, por estar negativamente relacionado à demanda.

$\mathrm{O}$ valor da passagem paga pelo passageiro dependerá das preferências dos usuários (dia da semana e horário do voo, antecedência da compra, escalas e conexões do voo, alta ou baixa temporada, espaçamento entre poltronas), como também por fatores diretos e indiretos a que o transporte aéreo está sujeito (preço do barril do petróleo e taxa de câmbio, etapa, grau de concorrência do mercado, densidade de demanda, porte e eficiência das aeronaves). Um estudo que decompõe os preços de passagens aéreas no Brasil pode ser encontrado em Póvoa e Oliveira (2013). Por estar relacionado com demais fatores é que na literatura o preço é considerado endógeno. Através dos relatórios da ANAC, foi possível avaliar o conceito de yield, agregado por região do país, no caso de Brasília, a Região Centro-oeste, sendo feita uma ponderação média de número de assentos semanais oferecidos pelas companhias aéreas das ligações entre pares de regiões (variando de aeroporto para aeroporto e mês). Os valores foram obtidos através dos relatórios da ANAC (primeiro semestre de 2013) e obtidos por solicitação a parte de forma desagregada por região. Os valores monetários estão em reais constantes de dezembro de 2013 e atualizados pelo Índice Nacional de Preços do Consumidor Amplo (IPCA) do Instituto Brasileiro de Geografia e Estatística (IBGE, 2014).

Há outra variável no modelo considerada endógena por estar relacionada ao yield. Para analisar a influência na demanda causada pelo preço e pela entrada de novos segmentos de consumidores (classes C e D, ao final dos anos
2000), foi criada uma interação entre as variáveis yield e ncon (novos consumidores, variável binária, configurada com valor 1 a partir de agosto de 2009), sendo esta a variável multiplicativa yield_ncon (ou seja yield multiplicada por ncon). A ascensão de novos segmentos de consumidores, em paralelo à entrada da companhia aérea Azul, em dezembro de 2009, fez com que a demanda provavelmente ficasse mais sensível ao preço. Por conta desses fatores, espera-se sinal negativo nessa variável, por estar negativamente relacionada à demanda.

O poder aquisitivo de uma região/população influencia na escolha do transporte a ser usado. Porém, o conceito de aquisição de bens, atividade econômica e/ou renda de uma população é de difícil ponderação. Por isso utilizou-se o consumo de energia elétrica como variável proxy para medição. No modelo foi tomado o consumo de energia elétrica, enel, porém poderia ser utilizada outra variável proxy, como o Produto Interno Bruto - PIB, caso este apresentasse desagregação regional.

Enel diz respeito ao consumo de energia elétrica nas regiões de origem e destino das ligações que envolvem o aeroporto de Brasília. É a energia elétrica consumida mensal total em GWh, na Região Centro-oeste, extraída a média geométrica simples do consumo das regiões do par origem-destino. Ao final, ponderada pelo número de assentos semanais oferecidos pelas companhias aéreas das ligações entre os pares de regiões (esse valor varia de aeroporto para aeroporto). Quanto mais energia elétrica consumida, pode-se deduzir que a economia na região está aquecida; logo, estando a demanda do transporte aéreo e a renda da população positivamente relacionadas, espera-se sinal positivo no modelo econométrico. Os dados são mensais e foram extraídos do Portal de estatísticas Ipeadata (Ipeadata, 2014). Através do teste Engle-Granger (Tabela 1), para análise de cointegração, é possível afirmar que as variáveis paxdl, enel e yield cointegram a 5\%, afastando a hipótese de variável espúria. Esse é mais um indício da importância das variáveis enel e yield para explicação da demanda.

Na Tabela 2 são apresentadas as estatísticas descritivas das variáveis paxdl, yield e enel. As unidades de medida dessas variáveis, respectivamente, são: passageiros domésticos locais (por unidade), tarifa média cobrada do passageiro por quilômetro $(\mathrm{R} \$ / \mathrm{km})$ e $\mathrm{GWh}$. 
Tabela 1 - Teste Engle-Granger para cointegração

\begin{tabular}{|c|c|c|c|c|c|}
\hline & & & $\mathrm{N}\left(1^{\circ}\right.$ pas & & 132 \\
\hline Tes & Àranger pare & gração & $\mathrm{N}$ (teste) & $=$ & 131 \\
\hline & Teste & $1 \%$ Valor & $5 \%$ Valor & & $10 \%$ Valor \\
\hline$Z(t)$ & Estatístico & Crítico & Crítico & & Crítico \\
\hline & $-3,961$ & $-4,406$ & $-3,807$ & & $-3,5$ \\
\hline
\end{tabular}

Tabela 2 - Estatística descritiva

\begin{tabular}{llllll}
\hline Variable & Obs & Mean & Std. Dev. & Min & Max \\
\hline paxdl & 132 & 612,2515 & 252,8052 & 290,1 & $1.527,206$ \\
yield & 132 & 56,22919 & 20,76013 & 26,60645 & 106,4475 \\
enel & 132 & 4,150621 & 0,585777 & 2,913724 & 5,329278 \\
\hline
\end{tabular}

Uma variável de teste inserida no modelo foi a interação entre enel e ncon (novos consumidores), resultando em enel_ncon, para testar uma diminuição de sensibilidade à renda, analisando se a demanda pode ser explicada através da influência da renda com a entrada de novas companhias aéreas. $\mathrm{O}$ sinal negativo significa que o usuário do transporte aéreo ficou menos sensível à atividade econômica, viaja mais por outros motivos e a atividade econômica não influi tanto quanto antes.

Outra variável proxy para medir a renda do consumidor e o aquecimento do mercado é o rcredit, também inserido no modelo. Essa variável é igual ao total de operações de crédito do setor privado no Brasil sobre o PIB nacional. Os dados foram coletados no portal de estatísticas Ipeadata e transformados em valores constantes de dezembro de 2012 com o uso do deflator IPCA. Apesar de não ser comumente utilizado como variável para estudos econométricos, o estudo de crédito do consumidor pode ser assumido como uma alternativa para análise do mercado, análise das atividades econômicas do consumidor. Por estar relacionada positivamente com o crescimento econômico e por isso com a demanda também, é que o sinal positivo é esperado. Através do Teste VIF (Variance Inflation Factor), todas as variáveis do modelo demonstraram forte multicolinearidade entre si à exceção da variável yield. De fato, a estatística VIF média ficou em 53,13 e o menor VIF individual calculado foi o da variável yield, que ficou em 4,95. O segundo menor VIF foi o da variável rcredit, em torno de 20,5.

Utilizando a variável proxy rcredit e a variável de novos consumidores ncon, criou-se a variável de interação entre elas, rcredit_ncon. Esta é mais uma variável-teste para estudar a possível influência que a economia e a entrada de novas companhias têm no consumidor, em especial na demanda aeroportuária. Supondo que a população esteja consumindo mais (economia aquecida) e a entrada de novas companhias aéreas aumente a competição no setor aéreo, esses dois fatores irão colaborar para o aumento da demanda; logo o sinal esperado dessa variável é o positivo.

\section{MODELAGEM ECONOMÉTRICA DE DEMANDA AEROPORTUÁRIA}

O modelo econométrico final do estudo de demanda doméstica local do Aeroporto Internacional de Brasília é apresentado na equação (1).

Além das variáveis já descritas no item 2, a equação apresenta a somatória de dummies de sazonalidade como variáveis de controle. Uma dummy, é uma variável binária (valor 1 ou 0) e serve para dar entradas de características qualitativas ao modelo. Considera que o que é não observável é inerente a ele. Aqui, a dummy da base que serve como comparativa às demais é a m_1 (mês de janeiro). A sazonalidade é um fator de influência para o crescimento ou diminuição das viagens aéreas, pois estão relacionadas ao preço das passagens. Esta diferença se deve ao período de férias/feriados, estações do ano (prin-

$\ln$ paxdl $=\beta_{0}+\beta_{1}$ yield $+\beta_{2}$ yield $\_$ncon $+\beta_{3}$ enel $+\beta_{4}$ enel $\_$ncon $+\beta_{5}$ rcredit

$+\beta_{6}$ rcredit_ncon $+\sum_{m} Y_{m}$ sazonalidade_mês_ $m+u$ 
cipalmente verão) e festividades (natal, ano novo, carnaval, páscoa). Com essa métrica pode-se destacar o efeito que a sazonalidade tem ao longo do ano em datas específicas no volume de viagens aéreas. Os únicos meses que passam no teste de hipótese (teste de significância t-Student) são: fevereiro, março, julho, setembro e dezembro, que são os mais representativos em demanda de passageiros. Sendo que comparativamente ao mês de janeiro, os meses de fevereiro, março e setembro tem demanda decrescente e os meses de julho e dezembro, crescente. A única variável que não passa no teste de hipótese é o rcredit, que está sendo testada como variável proxy para medir o consumo da população na Região Centro-oeste.

Para chegar ao modelo final, primeiramente foram assumidas as variáveis geradoras de dados (yield e enel) e foram feitos testes para adoção de outras que pudessem integrar ao modelo. Quando há inserção de séries temporais (dummies de sazonalidade), desconfia-se da presença de autocorrelação, sendo este o efeito do passado explicar o presente. Pôde-se comprovar a presença de autocorrelação de ordem 17 e assumiu-se a presença de heteroscedasticidade, tratando o modelo para isso.

Assumir que o modelo é heteroscedástico significa dizer que os erros não são independentes e não são identicamente distribuídos, não há quebra da Média Condicional Zero (MCZ), pois a média continua a ser zero, porém a variância deixa de ser constante. Com a presença de autocorrelação e heteroscedasticidade foi escolhido um estimador mais amplo que o OLS (Ordinary Least Squares) utilizado para o modelo clássico ou o 2SLS (Two Stage Least Squares), utilizando-se então o GMM2S (Generalized Method of Moments 2 Steps). Para uma discussão pormenorizada, vide Wooldridge (2012). Na Tabela 5 , a escolha aqui citada pode ser melhor avaliada através de testes e comparações entre os estimadores.

Entendendo que preço e demanda são endogenamente determinados, a variável yield induz endogenia ao modelo e, portanto, yield_ncon também será. Diversos são os motivos que podem causar a endogenia, dentre eles podem-se citar a má-especificação, erro de estimação, omissão de variáveis. Quando são incluídas variáveis irrelevantes, este fato não irá causar tantos danos, pois como são irrelevantes não irão explicar a variável dependente e nem serão correlacionadas com os demais regressores. Com o teste $t$-student a variável irrelevante já será identificada, ou se for mais de uma, podese utilizar um teste conjunto de nulidade. Já quando há omissão de variáveis ocorre viés. A omissão de variáveis relevantes prejudica as variáveis incluídas que tem alguma relação com as omitidas, mas se essa relação não existe, não existe viés também.

Aonde há endogenia, há quebra da Média Condicional Zero (MCZ). Para resolver esse problema econométrico é possível a utilização de proxies, mas como nem sempre essas são suficientes, pode-se instrumentar o modelo. Variáveis instrumentais são usadas para "explicar" a variável endógena, precisando estas ser bem correlacionadas com essa variável, mas ortogonais ao erro (independente linear ao erro). Caso haja uma relação fraca entre o instrumento e a variável endógena, haverá uma subidentificação, logo não auxiliará no problema. A variável instrumental tem como mecanismo excluir toda a endogenia "rodando" apenas a parte exógena das variáveis.

No caso, para que não haja viés por simultaneidade, por se tratar de preço e demanda, pois ambos são gerados conjuntamente, foram usados três instrumentos: lagyield, avfltime_ncon e lagavfltime2_ncon. Para controlar os não observáveis, utilizou-se dois instrumentos defasados (lagyield e lagavfltime2_ncon). Não observáveis omitidos são aproximados pelo valor de uma variável anterior. Por isso que variáveis defasadas normalmente funcionam bem como instrumentos, sendo bem relacionadas com as variáveis endógenas. A interação entre as novas companhias aéreas com o tempo médio de voo (em horas) das aeronaves pousando ou decolando, considerando voos regulares aqueles partindo do aeroporto de Brasília, também funciona como um bom instrumento. Pois, um dos condicionantes das tarifas aéreas é a etapa percorrida em cada operação realizada e tendo esse instrumento a interação com o ncon e uma das variáveis endógenas também, logo serão bem relacionadas. Os dados para essa variável (avfltime_ncon) que abrange apenas voos regulares, em uma base semanal da programação de voos das companhias aéreas (com periodicidade mensal), foram obtidos do HOTRAN (Horário de Transporte) e também através da ANAC (Agência Nacional de Aviação Civil). Os três instrumentos foram testados e passaram no teste 
Kleibergen-Paap Sub $\left(H_{0}=\right.$ equação subidentificada, instrumentos irrelevantes), no teste Cragg-Donald e Kleibergen-Paap Weak $\left(\boldsymbol{H}_{0}=\right.$ equação subidentificada, instrumentos fracos) e por último no teste J-Hansen ( $H_{0}=$ equação sobreidentificada, instrumentos válidos).

Ter um modelo bem especificado é o primeiro passo para que haja ajuste adequado de resultados. Para isso, foram feitos diversos testes de especificação, comparando o Erro Percentual Médio Absoluto (MAPE - Mean Absolute Percentage Error) entre as diversas hipóteses adotadas com o modelo preferido apresentado no item 5 da Tabela 4. Pelas características do mo- delo proposto, supunha-se que o modelo log-lin representaria mais corretamente o problema, o que pode ser comprovado através da Tabela 3 (linearidade versus não linearidade), pois este apresenta um erro menor que os demais, apesar de a diferença entre eles não ser representativa. Admitir um modelo log-lin é acreditar que esteja havendo um crescimento exponencial. A cada variação unitária de alguma das parcelas da equação, haverá um crescimento exponencial da demanda (variável dependente), aumentos uniformes de $\mathrm{x}$ causam aumentos mais que proporcionais a y e as taxas de crescimento de y serão constantes.

Tabela 3 - Resultados dos testes de especificação através do MAPE.

\begin{tabular}{|c|c|c|c|c|}
\hline \multirow[b]{2}{*}{ linear } & \multirow{2}{*}{\begin{tabular}{|l} 
Média \\
0,2286
\end{tabular}} & \multirow{2}{*}{$\begin{array}{l}\text { Desv. Padrão } \\
0,0396\end{array}$} & \multicolumn{2}{|c|}{ [95\% Interv. Conf.] } \\
\hline & & & 0,1466 & 0,3106 \\
\hline linlog & 0,2391 & 0,0414 & 0,1535 & 0,3246 \\
\hline loglin & 0,2111 & 0,0363 & 0,1361 & 0,2861 \\
\hline loglog & 0,2135 & 0,0375 & 0,1359 & 0,2911 \\
\hline \multicolumn{5}{|c|}{ Instrumentação versus não-instrumentação } \\
\hline & Média & Desv. Padrão & {$[95 \% \ln$} & \\
\hline OLS & 0,2048 & 0,0347 & 0,1329 & 0,2768 \\
\hline GMM & 0,2111 & 0,0363 & 0,1361 & 0,2861 \\
\hline
\end{tabular}

Subespecificação versus especificação

\begin{tabular}{|c|c|c|c|c|}
\hline & Média & Desv. Padrão & \multicolumn{2}{|c|}{ [95\% Interv. Conf.] } \\
\hline GMM_Sub & 0,2078 & 0,0343 & 0,1368 & 0,2788 \\
\hline GMM & 0,2111 & 0,0363 & 0,1361 & 0,2861 \\
\hline \multicolumn{5}{|c|}{ Estático versus dinâmico } \\
\hline & Média & Desv. Padrão & \multicolumn{2}{|c|}{ [95\% Interv. Conf.] } \\
\hline TS & 0,0960 & 0,0177 & 0,0594 & 0,1327 \\
\hline GMM & 0,2111 & 0,0363 & 0,1361 & 0,2861 \\
\hline
\end{tabular}

A Tabela 3 apresenta ainda, respectivamente, a análise do modelo instrumentado versus o não instrumentado e o subespecificado versus o especificado. Nas duas comparações o modelo preferido obteve um erro acima da hipótese alternativa, porém como a diferença não é significativa optou-se pelo modelo preferido (GMM). Pois, por ter duas variáveis naturalmente endógenas (yield e yield_ncon), o modelo clássico (OLS) não é indicado, sendo necessário um estimador que permita a entrada de variáveis instrumentais. Já na comparação entre subespecificação e especificação, supôs-se a ausência da maioria das variáveis exógenas, sendo excluí- das, portanto, enel_ncon, rcredit, rcredit_ncon, criando assim um modelo subespecificado e comparou-se ao modelo preferido. Como ambos os modelos apresentaram uma diferença ínfima no cálculo do erro percentual médio absoluto, continuou-se com o modelo preferido, pois a omissão de variáveis relevantes pode gerar viés. $\mathrm{Na}$ análise do modelo ts (time series) versus o modelo GMM (estático), verificou-se uma grande diferença no erro percentual médio absoluto, sendo que o modelo dinâmico mostra um erro menor que o estático. Os modelos dinâmicos são ótimos para previsões, porém apresentam problemas quando há muitas variáveis ex- 
plicativas. Costuma haver troca de sinais, significância comprometida, multicolineari dade, além de ter uma modelagem mais complexa. Em vista da possibilidade destes problemas, preferiu-se continuar com o modelo estático.

Foram realizados ainda arranjos em relação às variáveis-teste do modelo, sendo todas as tentativas para o mesmo estimador GMM2S; o intuito foi verificar a sensibilidade do modelo preferido. Para isso tem-se o modelo preferido (5) e comparativamente as subespecificações. $\mathrm{Na}$ Tabela 4, são apresentadas cinco hipóteses de modelos e suas respectivas elasticidades. $\mathrm{O}$ modelo 1 é composto apenas pelas variáveis núcleo-duro; já no modelo 2, além das variáveis do modelo 1, foi acrescida a variável-teste rcredit. No modelo 3, além do rcredit, foi testada a variável ncon, que não existe no modelo preferido (5). O modelo 4 é composto por todas as variáveis testes e as interações com enel e rcredit.

Através da análise da Tabela 4, foi possível observar que enel não é sensível às mudanças realizadas nos modelos e yield, por ser outra variável geradora de dados, também não apresenta grande variação. Já yield_ncon, por se tratar de uma interação com a variável ncon, acaba sendo abalada por omissão de variáveis em todos os modelos exceto no modelo 5. No modelo 3, com a presença de ncon, o desvio padrão aumenta, prejudicando ainda mais a variável $y i$ eld_ncon. É como se a variável ncon fosse "decomposta" em diversas partes, e quando ela aparece por inteira, causa multicolinearidade nas demais variáveis, prejudicando-as, como pode ser visto também no modelo 4 . Por isso, no modelo preferido foram utilizadas as iterações da variável ncon com as demais, mas não foi adicionada ela própria. Logo, no modelo 5 não houve viés por causa da falta da variável ncon, pois sua divisão em parcelas possibilitou melhor explicação. Pode-se observar também que a demanda é mais elástica em relação ao crédito (rcredit_ncon) do que a economia (enel_ncon), mesmo que os dois estejam interagindo com a mesma variável de novas companhias aéreas (ncon). O modelo 4 obteve um r-quadrado maior que os demais, porém isso apenas identifica que o acréscimo de mais variáveis, de fato, aumenta esse coeficiente.

Na Tabela 5 é apresentada mais uma análise de robustez do modelo preferido (3), mas agora todas as variáveis são comuns a todos os modelos, sendo diferenciado o estimador. Por se tratarem de metodologias diferentes e pelos outros modelos terem mais "ruído", é que os r-quadrados não são comparáveis. Além disso, o OLS não é indicado quando há presença de autocorrelação e heteroscedasticidade, precisando de um estimador mais amplo. Como o estimador 2SLS é um caso específico do GMM2S este foi descartado, também sendo preferido o modelo 3. Para a elasticidade da tarifa aérea (yield), há uma diferença de aproximadamente $38 \%$ entre os estimadores OLS e GMM2S.

Quando há desconfiança das variáveis instrumentais utilizadas no modelo, usa-se o estimador LIML (Limited Information Maximum Likelihood) como alternativa (Angrist e Pischke, 2009). Para verificação, testou-se com o estimador CUE (Continuous Updating Estimator), por este ser bastante sensível a instrumentos fracos (Mátyás e Sevestre, 2008). Porém, comparando os modelos 3, 4 e 5 pode-se observar que nenhuma variável perdeu a significância estatística com estes estimadores, eliminando a ausência de má-especificação por instrumentos fracos. Sendo assim, as análises de sensibilidade e robustez do modelo estão completas e pode-se reafirmar a preferência do modelo inicial.

\section{SIMULAÇÃO DOS IMPACTOS DE BEM-ESTAR ECONÔMICO}

Após o estudo e concepção do modelo econométrico da demanda para o Aeroporto Internacional de Brasília foi feita uma simulação de bem-estar econômico da demanda em relação ao custo do combustível. O objetivo foi utilizar um elemento de custo, no caso, o escolhido foi o do combustível para transmitir um choque no transporte aéreo e analisar quão impactante seria para a demanda um choque considerável desse elemento de custo. Para isso, foi simulado através de um contrafatual (cenário simulado alternativo ao observado em um dado período amostral ou extra-amostral) para o ano-base de 2012, com as estimativas das variáveis da tarifa aérea (yield e yield_ncon) e um choque significativo no custo do combustível de $50 \%$. As estimativas das variáveis referentes às tarifas aéreas foram as únicas a terem sido tomadas, pois somente o preço foi "perturbado" no choque de custo, em busca do deslocamento da demanda aeroportuária. $\mathrm{O}$ choque percentual, de participação dos custos, realizado irá impactar no crpk 
que é o custo médio operacional das companhias aéreas regulares. Foi necessário introduzir na base de dados o preço observado e a demanda observada no ano de 2012, pois foi realizada uma previsão intra-amostral (dentro da amostra) da demanda deste ano para esse novo cenário. Essa simulação resultou em uma nova demanda para aquele ano.

Tabela 4 - Análise de robustez - alteração na especificação

\begin{tabular}{|c|c|c|c|c|c|}
\hline & $\begin{array}{l}\quad(1) \\
\text { GMM2S- } \\
\text { reduzido } 1\end{array}$ & $\begin{array}{c}\quad(2) \\
\text { GMM2S- } \\
\text { reduzido } 2\end{array}$ & $\begin{array}{c}\text { (3) } \\
\text { GMM2S- } \\
\text { reduzido } 3\end{array}$ & $\begin{array}{l}\text { (4) } \\
\text { GMM2S- } \\
\text { completo } 1\end{array}$ & $\begin{array}{c}(5) \\
\text { GMM2S- } \\
\text { completo } 2\end{array}$ \\
\hline \multirow[t]{2}{*}{ yield } & $-0,2653^{\star *}$ & $-0,2331$ & $-0,3214^{* *}$ & $-0,4392^{\star \star \star}$ & $-0,4088^{* * *}$ \\
\hline & {$[0,133]$} & {$[0,173]$} & {$[0,154]$} & {$[0,099]$} & {$[0,108]$} \\
\hline \multirow[t]{2}{*}{ yield_ncon } & $-0,0037$ & $-0,0082$ & 0,1851 & 0,0978 & $-0,1481^{* *}$ \\
\hline & {$[0,029]$} & {$[0,038]$} & {$[0,172]$} & {$[0,092]$} & {$[0,070]$} \\
\hline \multirow[t]{2}{*}{ enel } & $1,8282^{* * *}$ & $1,6600^{* * *}$ & $1,6888^{\star * *}$ & $1,2980^{* * *}$ & $1,2363^{* * *}$ \\
\hline & {$[0,571]$} & {$[0,364]$} & {$[0,404]$} & {$[0,408]$} & {$[0,423]$} \\
\hline \multirow[t]{2}{*}{ rcredit } & & 0,1509 & $-0,0145$ & $-0,1463$ & $-0,1141$ \\
\hline & & {$[0,301]$} & {$[0,305]$} & {$[0,118]$} & {$[0,118]$} \\
\hline \multirow[t]{2}{*}{ ncon } & & & $-0,2067$ & $-0,6504^{* * *}$ & \\
\hline & & & {$[0,173]$} & {$[0,229]$} & \\
\hline \multirow[t]{2}{*}{ enel_ncon } & & & & $-0,1566$ & $-0,6325^{\star \star *}$ \\
\hline & & & & {$[0,279]$} & {$[0,173]$} \\
\hline \multirow[t]{2}{*}{ rcredit_ncon } & & & & $0,7284^{* * *}$ & $0,8126^{\star * *}$ \\
\hline & & & & {$[0,171]$} & {$[0,196]$} \\
\hline$R$ quadrado & 0,8431 & 0,8458 & 0,8144 & 0,8974 & 0,8716 \\
\hline RMSE & 0,1514 & 0,1507 & 0,1661 & 0,1245 & 0,1387 \\
\hline F Estatística & 44,374 & 59,550 & 90,424 & 136,525 & 52,700 \\
\hline F P-valor & 0,0000 & 0,0000 & 0,0000 & 0,0000 & 0,0000 \\
\hline RESET & 2,245 & 2,822 & 5,485 & 0,069 & 0,189 \\
\hline RESET P-valor & 0,1340 & 0,0930 & 0,0192 & 0,7920 & 0,6637 \\
\hline KP Estatística & 6,510 & 5,465 & 2,469 & 3,412 & 6,045 \\
\hline KP P-valor & 0,0386 & 0,0650 & 0,2908 & 0,1815 & 0,0487 \\
\hline J Estatística & 0,054 & 0,056 & 1,753 & 1,382 & 0,940 \\
\hline J P-valor & 0,8153 & 0,8124 & 0,1854 & 0,2396 & 0,3323 \\
\hline
\end{tabular}

Notas:

Erros padrões estimados em colchetes

Representações de $p$-valor: ${ }^{* *} p<0,01,{ }^{* *} p<0,05,{ }^{*} p<0,10$

Elasticidades estimadas na média amostral, dummies de sazonalidade mensal omitidas da tabela.

A simulação é apresentada na Tabela 6, onde na segunda coluna estão os valores-base para comparação com os contrafatuais. Houve em 2012, no Aeroporto Internacional de Brasília, uma demanda de 13,13 milhões de viagens. Supondo um choque na demanda com um aumento significativo de $50 \%$ no custo do combustível, se não houver repasse (preço médio da passagem permanece o mesmo) para o usuário desse aumento, o número de viagens não será afetado, nem as receitas totais (número de via- gens vezes o preço). Isso poderia acontecer se houvesse um aumento repentino no preço do combustível e as companhias não conseguissem repassar por conta da venda antecipada de passagens. Outra hipótese seria talvez a alta concorrência entre companhias e que por isso não conseguissem aumentar o preço com o receio da perda de mercado. Com essas suposições, podem-se fazer inferências quanto aos excedentes do consumidor e do produtor. 
Tabela 5 - Análise de robustez - alteração nos estimadores

\begin{tabular}{|c|c|c|c|c|c|}
\hline & (1) & (2) & (3) & (4) & (5) \\
\hline & OLS & 2SLS & GMM2S & LIML & CUE \\
\hline \multirow[t]{2}{*}{ yield } & $-0,2531^{* * *}$ & $-0,3848^{\star * *}$ & $-0,4088^{* * *}$ & $-0,3883^{* * *}$ & $-0,4218^{* * *}$ \\
\hline & {$[0,086]$} & {$[0,111]$} & {$[0,108]$} & {$[0,111]$} & {$[0,100]$} \\
\hline \multirow[t]{2}{*}{ yield_ncon } & $-0,0271$ & $-0,1783^{\star *}$ & $-0,1481^{* *}$ & $-0,1822^{\star *}$ & $-0,1382^{*}$ \\
\hline & {$[0,049]$} & {$[0,078]$} & {$[0,070]$} & {$[0,079]$} & {$[0,082]$} \\
\hline \multirow[t]{2}{*}{ enel } & $1,6218^{* \star *}$ & $1,2465^{\star \star \star}$ & $1,2363^{\star \star *}$ & $1,2372^{* \star *}$ & $1,2029^{* * *}$ \\
\hline & {$[0,320]$} & {$[0,423]$} & {$[0,423]$} & {$[0,425]$} & {$[0,415]$} \\
\hline \multirow[t]{2}{*}{ enel_ncon } & $-0,8467^{* * *}$ & $-0,6592^{* \star *}$ & $-0,6325^{\star \star *}$ & $-0,6544^{* * *}$ & $-0,5986^{\star * *}$ \\
\hline & {$[0,198]$} & {$[0,176]$} & {$[0,173]$} & {$[0,176]$} & {$[0,188]$} \\
\hline \multirow[t]{2}{*}{ rcredit } & $-0,0176$ & $-0,0640$ & $-0,1141$ & $-0,0655$ & $-0,1171$ \\
\hline & {$[0,116]$} & {$[0,130]$} & {$[0,118]$} & {$[0,131]$} & {$[0,120]$} \\
\hline \multirow[t]{2}{*}{ rcredit_ncon } & $0,8881^{* * *}$ & $0,8619^{* * *}$ & $0,8126^{* * *}$ & $0,8612^{* * *}$ & $0,7600^{* * *}$ \\
\hline & {$[0,225]$} & {$[0,204]$} & {$[0,196]$} & {$[0,203]$} & {$[0,236]$} \\
\hline R quadrado & 0,8880 & 0,8695 & 0,8716 & 0,8686 & 0,8702 \\
\hline RMSE & 0,1302 & 0,1399 & 0,1387 & 0,1403 & 0,1395 \\
\hline F Estatística & 111,359 & 50,304 & 52,700 & 49,214 & 52,182 \\
\hline F P-valor & 0,0000 & 0,0000 & 0,0000 & 0,0000 & 0,0000 \\
\hline RESET & 1,851 & 0,401 & 0,1890 & 0,4055 & 0,1165 \\
\hline RESET P-valor & 0,1736 & 0,5265 & 0,6637 & 0,5242 & 0,7329 \\
\hline
\end{tabular}

\section{Notas:}

Erros padrões estimados em colchetes

Representações de $p$-valor: ${ }^{* *} p<0,01,{ }^{* *} p<0,05,{ }^{*} p<0,10$

Elasticidades estimadas na média amostral. Dummies de sazonalidade mensal omitidas.

O excedente do consumidor pode ser obtido, como mostra a Equação (2), pelo cálculo da integral da área abaixo da curva de demanda $\mathrm{D}(\mathrm{x})$, subtraindo o preço unitário do bem multiplicado pela quantidade $(\bar{x})$. Essa relação diz respeito ao valor que um consumidor estaria disposto a pagar, e o valor que ele realmente paga. Já o excedente do produtor pode ser calculado, pela Equação (3), como sendo a área total do preço praticado no mercado $(\bar{p})$ multiplicado pela quantidade oferecida $(\bar{x})$ subtraindo a área abaixo da curva de oferta $\mathrm{S}(\mathrm{x})$. Esse valor corresponde ao ganho do produtor (com baixo custo) em relação às vendas do produto ao preço de mercado.

$$
\begin{aligned}
& C S=\int_{0}^{\bar{x}} D(x) d x-\bar{p} \cdot \bar{x} \\
& P S=\bar{p} \cdot \bar{x}-\int_{0}^{\bar{x}} S(x) d x
\end{aligned}
$$

Logo, um possível aumento sem repasse não acarretaria em alteração no excedente do consumidor (nível de satisfação em unidade mo- netária do consumidor). Já com o aumento do custo do combustível, sem repasse, o excedente do produtor (lucro obtido pelo produtor pelo maior preço que o consumidor aceitaria comprar) tem uma queda acentuada em relação ao cenário-base. $\mathrm{O}$ bem-estar econômico é dado pela soma do excedente do consumidor e do excedente do produtor, seria o "equilíbrio" do mercado. $\mathrm{O}$ excedente do consumidor por passageiro (quantia que o passageiro estaria disposto a pagar) seria em torno de 514,6 reais, quantia essa que a companhia aérea deixou de ganhar e que jamais recuperará.

O poder de monopólio pode ser medido através do Índice de Lerner (Pindyck e Rubinfeld, 2013), dada pela Equação (4). Logo, o mark-up é dado pela diferença entre o preço médio e o custo marginal, dividido pelo preço médio. Esse valor é igual ao inverso da elasticidade da curva de demanda da empresa multiplicado pelo número de empresas, no caso de um duopólio $\mathrm{n}=2$.

O poder de monopólio pode ser medido através do Índice de Lerner (Pindyck e Rubinfeld, 2013), dada pela Equação (4). Logo, o 
mark-up é dado pela diferença entre o preço médio e o custo marginal, dividido pelo preço médio. Esse valor é igual ao inverso da elasticidade da curva de demanda da empresa multiplicado pelo número de empresas, no caso de um duopólio $\mathrm{n}=2$.

$$
L=\frac{(P-C m g)}{P}=\frac{1}{n \cdot E_{d}}
$$

Quando com esse choque há repasse para o consumidor, as viagens diminuem, tendo uma baixa de $11,8 \%$, o preço médio aumenta em 18,3\%, como também o mark-up (preço médio menos o custo marginal), que mede o poder do mercado. As receitas totais não aumentam significativamente, pois os custos totais não aumentam tanto também. Com o repasse nas tarifas aéreas uma parcela dos custos pode ser diluída não impactando tão negativamente para as companhias aéreas. $\mathrm{Na}$ verdade, o repasse integral faz com que as companhias aéreas lucrem $4,4 \%$. Nesse momento há diminuição no excedente do consumidor e aumento no excedente do produtor. Lembrando que o objetivo de uma empresa é obter lucro e sempre tomará a posição que o maximiza.

No cenário $\mathrm{C} 3$, com o aumento de $50 \%$ no custo do combustível, assume-se um arrefecimento da concorrência, dado que nem todas as companhias aéreas conseguem suportar o choque, e que as firmas estabelecidas suavizam os movimentos competitivos de forma a concorrer como se fossem apenas duas grandes companhias (duopólio). Logo, os preços das passagens aéreas são duramente afetados, um preço médio de 587,25 reais (aumento de 67\%), por conta disso há uma diminuição de $37 \%$ na demanda. Um indicador para o poder de monopólio é o mark-up que cresce $249 \%$, esse grande aumento demonstra a inelasticidade da demanda. A quantia que o consumidor estaria disposto a pagar diminui para 326,00 reais e o bem-estar econômico total diminui em $17 \%$. As hipóteses realizadas no cenário $\mathrm{C} 3$ com a diminuição das firmas ou o modelo de concorrência efetuado por elas (duopólio) é o oposto da ação realizada pela variável ncon, onde a entrada de novas companhias aéreas estimula a concorrência, havendo, por conseguinte, diminuição de preços e aumento da demanda.

Tabela 6 - Simulação do bem-estar econômico da demanda.

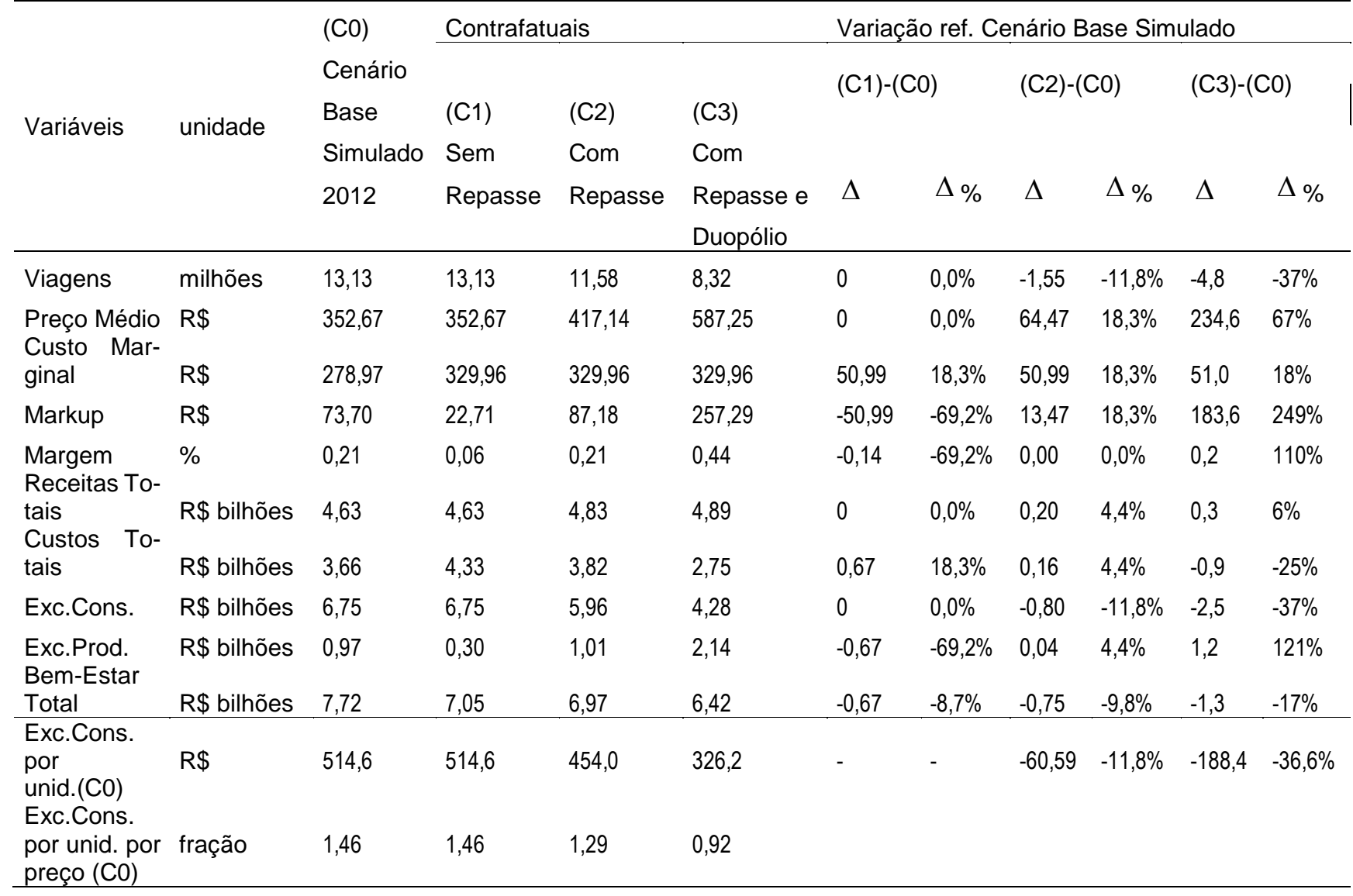




\section{CONCLUSÃO}

A partir deste trabalho foi possível estabelecer um modelo econométrico que melhor representasse o comportamento da demanda doméstica local do Aeroporto Internacional de Brasília. Da mesma forma que Ryerson e Hansen (2013), o modelo foi desenvolvido a fim de simular o impacto do preço do combustível nas políticas das companhias aéreas. Diferentemente dos autores, que focaram nos possíveis aumentos de custos dos preços do combustível, no presente estudo buscou-se avaliar o efeito final em métricas de bem-estar econômico. Foram simulados cenários, que em última instância deram suporte aos resultados. Os resultados corroboram as descobertas anteriores da literatura exemplos sendo o próprio estudo de Ryerson e Hansen (2013), além de Chao e Hsu (2014) quanto ao provável repasse de custos das companhias aéreas dada a dificuldade de obter eficiências compensatórias.

Para desenvolver o modelo foram efetuados testes de heteroscedasticidade, autocorrelação, controle sazonal, análise de endogenia, escolha de variáveis, análises de correlação (estatísticas descritivas). Além da contribuição do uso de variáveis instrumentais para controle de endogenia. Note novamente que na Tabela 4, no modelo preferido (5), a hipótese de equação subidentificada é rejeitada a 5\% com o teste Kleibergen-Paap sub e que a hipótese de sobreidentificação é mantida através do teste JHansen com 33\%, demonstrando que as variáveis instrumentais da equação são válidas. Foram utilizados também modelos teóricos de comportamento das firmas, aplicando parâmetros estimados pelo modelo econométrico estabelecido como preferido, através dos quais foram realizadas simulações de impactos de bem-estar econômico.

Com três cenários distintos $(\mathrm{C} 1, \mathrm{C} 2$ e $\mathrm{C} 3)$ foi possível analisar o impacto que um aumento de $50 \%$ no custo do combustível causaria no mercado. Por ser um choque na parcela de custo, o primeiro impacto será sentido pelas companhias aéreas. Os três cenários apresentaram diferentes posições que as firmas tomam por conta desse choque. Em contrapartida, a demanda irá se posicionar de acordo com o que ela está disposta a pagar. Se isso coincidir com a estratégia da firma, haverá aumento no bem-estar econômico; caso contrário, haverá diminuição da de- manda.

No cenário $\mathrm{C} 1$, foi mostrado o que aconteceria se com o choque no custo do combustível as companhias decidissem não repassar esse custo nas tarifas aeroportuárias, arcando com todas as despesas. De qualquer forma, esse comportamento faria com que o usuário não sentisse o aumento dos custos, pois o preço da passagem aérea não seria alterado e com isso o número de viagens permanece o mesmo. $\mathrm{O}$ não repasse de custos demonstra um baixo poder de mercado, calculado pelo mark-up que diminuiu em 69,2\%; logo a demanda se mostra bastante elástica. As receitas totais não foram aumentadas. Nos cenários C2 e C3 foi testado quando as companhias aéreas tomam atitudes de repasse para o usuário do valor da passagem, mas a concorrência entre elas toma diferentes encaminhamentos. No cenário C2 as companhias aéreas aumentam o preço da passagem contrabalanceando o aumento do custo do combustível. Há diminuição do número de viagens, porém mesmo assim há um lucro de 4,4\% (em relação ao $\mathrm{C} 0$ ) para as companhias aéreas. $\mathrm{E}$ no cenário $\mathrm{C} 3$, as firmas começam a agir como um duopólio, pela diminuição da concorrência entre elas. Logo, os preços aumentam expressivamente (67\%), a demanda diminui ainda mais que no cenário $\mathrm{C} 2$, mas o lucro das companhias aéreas fica em torno de $6 \%$ maior que no cenário $\mathrm{C} 0$. Houve uma diminuição de $17 \%$ do bem-estar econômico total, demonstrando o desequilíbrio entre o excedente do produtor e do consumidor, em relação ao equilíbrio estabelecido no cenário-base simulado $\mathrm{C} 0$.

Com os três cenários contrafatuais analisados é possível afirmar que um choque expressivo no custo do combustível irá impactar a demanda, se houver repasse integral do custo para o usuário, como visto nos cenários $\mathrm{C} 2$ e C3. Logo, o elemento de custo analisado "combustível" é um fator importante na análise de demanda, pois influencia diretamente os preços médios das passagens aéreas, transmitindo o impacto dos preços para a demanda. O presente estudo aponta para um visível déficit do excedente do produtor incorrido pelas empresas no cenário em que elas não repassam os aumentos, sendo muito provável que, dadas as perdas, as companhias não consigam evitar os reajustes de preços de passagens. Nossa análise mostra que o pior 
cenário é aquele em que as empresas aproveitam a situação para deixarem de concorrer efetivamente, instaurando um duopólio de fato. Nesse caso, o excedente do consumidor cai $37 \%$. Com essa análise foi possível verificar o poder de monopólio das companhias aéreas, o lucro alcançado com o repasse aos usuários, a intensidade da influência do repasse integral dos custos na demanda.

\section{AGRADECIMENTOS}

A primeira autora gostaria de agradecer a Capes pelo auxílio financeiro. $\mathrm{O}$ terceiro autor agradece o CNPq e a Fapesp pelo auxílio financeiro.

\section{REFERÊNCIAS}

ANAC (2013) Tarifas aéreas domésticas - $1^{\circ}$ Semestre de 2013 (29a ed.). Agência Nacional de Aviação Civil.

Angrist, J. D. e J.-S. Pischke (2009) Mostly Harmless Econometrics - An Empiricist's Companion. Princeton University Press. DOI: $10.1057 /$ be.2009.37.

Basso, L. J. e A. Zhang (2008) On the Relationship between Airport Pricing Models. Transportation Research Part B, v. 42, n. 9, p. 725-735. DOI: 10.1016/j.trb.2008.01.005.

Chao, C. - C. e C. - W. Hsu (2014) Cost Analysis of Air Cargo Transport and Effects of Fluctuations in Fuel Price. Journal of Air Transport Management, v. 35, p. 51-56. DOI: 10.1016/j.jairtraman.2013.11.010.

Hsu, C. - I. e W. - Y. Eie (2013) Airline Network Design and Adjustment in Response to Fluctuation in Jet Fuel Prices. Ma- thematical and Computer Modelling, v. 58, p. 1791-1803. DOI: 10.1016/j.mcm.2013.04.005.

Infraero, Empresa Brasileira de Infraestrutura Aeroportuária, 2014. > http://www.infraero.com.br/images/stories/Estatistica/2013/dez.pdf> (Fevereiro, 2014).

IBGE, Instituto Brasileiro de Geografia e Estatística, 2014. < http://www.ibge.gov.br/home/> (Fevereiro, 2014)

Ipeadata, Instituto de Pesquisa Econômica Aplicada, 2014 < http://www.ipeadata.gov.br/> (Fevereiro, 2014)

Lim, S. H. e Y. Hong (2014) Fuel Hedging and Airline Operating Costs. Journal of Air Transport Management, v. 36, p. 33-40. DOI: 10.1016/j.jairtraman.2013.12.009.

Lu, C.-C. e R. I. Pagliari (2004) Evaluating the Potential Impact of Alternative Airport Pricing Approaches on Social Welfare. Transportation Research Part E, v. 40, n. 1, p. 1-17. DOI: 10.1016/S1366-5545(03)00031-0.

Mátyás, L. e P. Sevestre (2008) The Econometrics of Panel Data ( $3^{\circ}$ ed.). Springer.

Pindyck, R. S. e D. L. Rubinfeld (2013) Microeconomics ( $8^{\circ}$ ed.). Pearson.

Póvoa, H. e A. V. M. Oliveira (2013) Econometric analysis to estimate the impact of holidays on airfares. Journal of Transport Literature, v. 7, n. 2, p. 284-296. DOI: 10.1590/S223810312013000200015

McKinsey\&Company (2010) Estudo do Setor de Transporte Aéreo do Brasil: relatório consolidado. Rio de Janeiro.

Ryerson, M. S. e M. Hansen (2013) Capturing the Impact of Fuel Price on Jet Aircraft Operating Costs with Leontief Technology and Econometric Models. Transportation Research Part C, v. 33, p. 282-296. DOI: 10.1016/j.trc.2011.05.015.

Wooldridge, J. M. (2012) Introductory Econometrics - A Modern Approach ( $2^{\circ}$ ed.) CENGAGE Learning. 